\title{
PRÁTICAS DISCURSIVAS SOBRE VIOLÊNCIANA ESCOLA: UMA INVESTIGAÇÃO SOBRE A VISÃO DOS ALUNOS
}

\author{
DISCURSIVE PRATICES ON VIOLENCE AT SCHOOL: AN \\ INVESTIGATION ABOUT THE STUDENTS' VISION
}

JANAÍNA RODRIGUES DE SOUSA ${ }^{1}$

\author{
PANDORA GRAMSCI SOARES VASCONCELOS ${ }^{2}$
}

\begin{abstract}
RESUMO: A presente pesquisa revisa literaturas associadas à identificação das principais formas de violência escolar na perspectiva de estudantes do ensino médio, tornando possível identificar produções para análise de narrativas sobre o motivo da violência, e, sua relação com formas existentes de enfrentamento deste comportamento no âmbito escolar. Para tanto, as concepções sobre violência no âmbito educacional se encaminham para a compreensão dos processos simbólicos recorrentes na escola. Em questões metodológicas, será apresentado com abordagem qualitativa, estando aliado à natureza da pesquisa aplicada, produzindo aportes teóricos para a mediação no processo de investigação sobre a percepção de jovens no ensino médio. Os resultados, aliados a uma teoria psicanalítica, buscou interpretar conteúdos inconscientes de vivências primitivas e vínculos atuais na vivência de grupos, para, então, demonstrar motivações que exibem aspectos defensivos e projetivos influenciáveis na convivência entre pares.
\end{abstract}

PALAVRAS-CHAVES: Discurso; Psicanálise; Violência na escola.

ABSTRACT: The present research revises literatures associated with the identification of the main forms of school violence in the perspective of high school students, making it possible to identify productions for analysis of narratives on the reason for violence, and their relationship with existing ways of conceptions about this behavior in school. To do so, the conceptions on educational violence are forwarded to the understanding of the recurring symbolic processes in the school. In methodological issues, it will be presented with a qualitative approach, being allied to the nature of the applied research, producing theoretical contributions to mediation in the research process on the perception of young people on high school. The results, allied to a psychoanalytic theory, sought to interconit unconscious content of primitive experiences and current lines in the experience of groups, so to demonstrate motivations that exhibit influencible defensive and projective aspects in the coexistence of peer.

KEY-WORDS: Discourse. Psychoanalysis. Violence at school.

\footnotetext{
${ }^{1}$ Graduanda em Licenciatura em Ciências Sociais - Universidade Federal do Piauí (UFPI), bolsista pelo Programa de Incentivo a Bolsas de Iniciação à Docência (PIBID) e membro voluntária no Núcleo Interdisciplinar de Pesquisa em Psicanálise, Sexualidade e Contemporaneidades (NIPPSEC).

${ }^{2}$ Graduanda em Bacharelado em Ciências Sociais - Universidade Federal do Piauí (UFPI).
} 


\section{INTRODUÇÃO}

O presente documento apresenta os resultados de pesquisa sobre a concepção dos alunos do Ensino Médio público estadual sobre a violência na escola. Com a finalidade de revisar a literatura associada a identificação as principais formas de violência na escola, assim como buscar os significados atribuídos a violência na perspectiva de escolares do ensino médio, identificar produções que auxiliem na análise de narrativas dos escolares sobre o motivo da violência na escola e, por fim, identificar as formas existentes de enfrentamento a violência para o âmbito escolar. Dessa maneira, ocorreu a coleta de proposições e recomendações bibliográficas com vistas para a construção de um referencial teórico que provoque reflexões e estratégias para a progressão da pesquisa.

O estudo de perspectiva da escola sociológica francesa de abordagem para as situações de violência na escola, de Charlot (2002), que registra explosões violentas no ambiente escolar desde o século XIX, para lembrar que este não é um fenômeno novo, mas que é associado ao campo das emoções e que assim se vale de novas formas de expressão para permanecer atualizado nas ocorrências escolares.

Encontram-se dentre tais expressões o registro de violência contra o professor, o perfil de idade cada vez menor, os fatores externos de vulnerabilidade assim como lembra que situações sutis são igualmente geradoras desse temor. O contexto transmite a quebra de representações sociais importantes e apresenta o estabelecimento da situação de angústia que esta populaçãoé exposta. Logo, é possibilitado o alcance do entendimento de que a violência não é uma mera condição acidental e passa a ser compreendida como um fenômeno estrutural que alimenta a produção de afetos no qual aponta a perspectiva psicanalítica.

Recentemente, o relatório da UNICEF (2017) sobre a violência na vida de crianças e adolescentes, conferiu um tópico especial para a questão da violência na escola onde caracteriza a frequência e as principais ocorrências que esta população está exposta. O quantitativo revelado impressiona e é intensificado pelo retrato das ocorrências que contemplam castigos corporais, abuso sexual e homicídios como as principais formas de violência na escola. A expressividade dos indicadores sinaliza o estudo das concepções sobre violência no âmbito educacional como um caminho importante para compreensão dos processos simbólicos que ocorrem espaço escolar. 
Portanto, a face típica da violência na escola ao redor do mundo, destacada pelo documento, mostra que 1 a cada 3 indivíduos escolares já experienciaram o bullying formando o contingente de 130 milhões. Do mesmo modo estão 17 milhões de estudantes que admitem que já intimidaram alguém no ambiente escolar. Além disso, existe uma população de 732 milhões, 1 a cada 2 estudantes, que reside em lugares onde os castigos físicos dentro da escola não é integralmente proibido. O que significa dizer que metade da população em idade escolar está exposta a violência permitida é oriunda do ambiente escolar. Nos últimos 25 anos foram registrados 59 tiroteios em 14 países, nos quais resultaram em pelo menos uma morte por episódio. Nesta situação a organização ressaltou que 3 a cada 4 episódios de tiroteios na escola ocorreram nos Estados Unidos, país que a constituição resguarda o direito do povo de manter portar armas. Estes dados remetem a necessidade de considerar os fatores externos à escola que a posicionam em situações de vulnerabilidade.

No Brasil, através da lei $\mathrm{n}^{\circ} 1.3431$ de abril de 2017, foi criado um sistema de proteção integral a crianças e adolescentes vítimas ou testemunhas de violência que organiza o sistema de garantias de direitos (SDG) como um mecanismo para prevenir e coibir a violência desta população. Nestes termos, corresponde com as normativas nacionais e internacionais vigentes que preconizam e estabelecem sobre a proteção integral, à condição peculiar de desenvolvimento e prioridade absoluta. À vista disso, a legislação dialoga com a perspectiva psicanalítica quando considera a atenção para a realidade inscrita na infância e na adolescência.

Diante dos dados é possível a comparação com a conjuntura nacional no referido problema. A Pesquisa Nacional de Saúde do Escolar (PenSE, 2015) reitera que a violência escolar e a violência social interagem de modo que promovem, entre si, uma coexistência. Isso retrata que o ambiente escolar e o familiar que, em princípio, são entendidos como provedores de proteção e saúde estão sinalizados, paradoxalmente, como espaços suscetíveis a multiplicação de violências. Aquilo que é entendido como situações de violência na escola ocorre dentro de uma conjuntura que traz um caráter cíclico, principalmente em suas formas de enfrentamento.

A psicanálise afirma que a importância das experiências infantis para entender as formas de sofrimentos que se pode interpretar como situações de violência. Em psicanálise é deixado de lado a necessidade de delimitar o que seria violência em nome de um coletivo, por muitos motivos que, dentro deste contexto, podemos associar ao respeito à subjetividade individual que atravessa o sujeito no processo de constituição. Igualmente, 
por compreender que uma definição de violência em situações práticas é facultada àquele que detém o signo do poder, e também por observar a violência como um sintoma social, onde propõe o questionamento sobre seu pretexto dentro de um processo mental.

Em uma análise de experiência de produção feita por Brasil (2015) mostra que existem dispositivos narcísicos que relacionados a objetos culturais, transformam-se em recurso para simbolizar a violência e angústia em ambientes escolares e sobre esse aspecto posiciona o aprofundamento da teoria pulsional freudiana que coloca a agressividade como uma expressão necessária e constitutiva enquanto a violência é tomada como parte do processo de anulação do outro. Assim podemos entender a violência como uma interpretação, ou atribuição de sentidos ao processo de transformação que ocupa nossa percepção de mundo sob diversas perspectivas e que, portanto, é uma questão improdutiva aquela que busca uma definição de violência, haja vista a abordagem já mencionada para violência em psicanálise.

A agressividade, em Lacan (1953), é tomada como qualquer intervenção que desmonte o objeto que o sujeito criou para satisfazê-la. Nessa abordagem a violência é tomada como um dos nomes daquilo que é real, porém difícil de posicionar. A psicanálise então, de modo diferente de outras abordagens, não facilita uma definição sobre violência em nome de barrar a sensação de um entendimento pleno sobre tal questão. Nesse sentido Lacan (1953/1998, 252-253) complementa que a abordagem psicanalítica não considera as situações de violência como a principal relevância a ser considerada, mas que o perigo está na necessidade capturá-la dentro de uma condição objetiva e assim renovar a situação de alienação.

O campo da Psicologia adiciona a importância de observar as representações sociais nos ambientes de aprendizagem, por entender que os caminhos para aferir o desempenho não ocorrem num "vazio social", mas encontram-se repletos de significações atribuídas pelos sujeitos envolvidos (Alves-Mazzoti 2001, 2008, 2016). Todavia, também reforça que a atenção com as subjetividades, em suas singularidades, estão comprometidas pelo modelo social estabilizado que coaduna no sistema de educacional. Eis que as manifestações de violência se dão através da relação com o processo de inserção social do indivíduo, estudada através da psicanálise como uma fase de separação, que pode ser observada desde as experiências nas relações familiares na infância até os acontecimentos sociais que envolvem o indivíduo em toda sua trajetória.

Olhar a violência sob este aspecto, é pensar nas condições em que a sociedade vem sendo normatizada e como se constitui o processo de saúde-doença vivenciados nos 
dias de hoje. Neste sentido, a violência escolar é observada como um fenômeno contínuo que silencia e perturba o caminho do aprendizado, em termos weberianos, é estabelecida nessa conjuntura a relação de "domesticação do domesticado", ordenado por um problema de saúde pública, no qual é reiterada a oportunidade de pensar no indivíduo como detentor de um espaço e processo psíquico difusor de diferentes formas de violência.

Para além dos fenômenos observados a psicanálise lacaniana observa também o contexto cultural como curso importante para a análise das subjetividades de cada época (Lacan, 1953/1998: 322). Assim, para a psicanálise o encontro com a violência está em acordo com a linguagem emitida em um dado contexto histórico-social que permite observar as formas de expressões dos sujeitos para as mesmas situações. O estudo sobre as múltiplas violências da violência na escola, de Bringiotti, Kryveniuk e Lasso (2004), reconhece pontos da história educacional, situações de maltrato, nível socioeconômico e educacional da mãe como potenciais de vulnerabilidade para violência na escola.

Todavia, é importante lembrar dos jovens como principais atores, mas não únicos, desse contexto e que nem todos usam dessa forma de expressão para comunicação de sofrimento. Nas investigações, de Freud (1915/1996), sobre a energias que circulam no aparelho psíquico, a psicanálise associa estas situações a partir da ideia de angústia. Portanto, levando em conta uma disposição antropológica a angústia é sinalizada nas situações de separação, que provoca o vazio constituinte do sujeito. Em síntese, podemos dizer que a angústia e a violência incidem na subjetividade pela carência associada às funções maternas e paternas (NOGUEIRA, 2001).

O investimento deste estudo atravessa a percepção dos jovens sobre as principais formas de violência, para tanto, retomamos o cenário das normas do direito e da justiça, no Estado brasileiro, que reconhece como formas de violência (Art. 4', lei $\left.\mathrm{n}^{\circ} 13341 / 17\right) 1$. violência física, quando ofende a integridade ou saúde corporal ou lhe cause sofrimento físico; 2. violência psicológica, como conduta de discriminação, depreciação ou desrespeito em relação à criança ou ao adolescente mediante ameaça, constrangimento, humilhação, manipulação, isolamento, agressão verbal e xingamento, ridicularização, indiferença, exploração ou intimidação sistemática que possa comprometer seu desenvolvimento psíquico ou emocional, alienação parental, conduta que exponha a criança ou o adolescente, direta ou indiretamente, a crime violento contra membro de sua família ou de sua rede de apoio; 3. violência sexual, conduta que coaja a criança ou o adolescente a praticar ou presenciar conjunção carnal ou qualquer outro ato libidinoso, inclusive exposição do 
corpo em foto ou vídeo por meio eletrônico ou não, que compreenda situações de abuso ou exploração sexual e tráfico de pessoas;

4.violência institucional, entendida como a praticada por instituição pública ou conveniada, inclusive quando gerar revitimização.

A forma da lei citada, estabelece ainda a criação de centros integrados de atendimento às crianças e aos adolescentes com equipe multidisciplinar especializada. Conhecida como lei da escuta assistida, visto que redefine o funcionamento dos serviços de atenção a pessoas em situações de violência, no âmbito do Sistema Único de Saúde (SUS) com oferta de atendimento humanizado e escuta qualificada. Dessa maneira fica instituído o procedimento de escuta qualificada, no artigo $7^{\circ}$, pela rede de proteção e de tomada de depoimento especial, condicionada a autoridade policial e judicial, no artigo $8^{\circ}$. Considerando a escola como dispositivo importante de oitiva, podemos sugerir como barreira para a efetivação da escuta assistida a ausência do SUS no âmbito da secretaria de educação onde é localizado, primeiramente, o escolar. Em diálogo com este estudo, esta lei reitera a necessidade de atenção, análise e reflexão sobre as percepções dessa população nos casos de violência.

$\mathrm{Na}$ prática, o comportamento psicossocial do sujeito é tratado, sobretudo, em termos de um funcionamento orgânico manipulável que culminam em situações de medicalização que ocorrem seja através de psicofármacos ou por determinações normativas que não contemplam o perfil multifacetado, subjetivo e peculiar da juventude. Os entendimentos que movimentam a perspectiva do disciplinamento de corpos, com a medicalização da educação se tornam pertinentes quando considerados outros componentes importantes envolvidos, como as relações familiares e os indicadores sociodemográficos (CRUZ, FERRAZZA, JUNIOR, 2014). Isto é, as expressões individuais de violência estão, como já foi dito, legitimadas no processo de inserção social, considerada pelos estudos de saúde como indicadores sociodemográficos e relações familiares, porém pouco acolhido diante dos discursos organicistas.

O olhar a violência sob este aspecto, permite entendê-la como um exemplo do manejo dado às questões sociais da juventude e, assim como possibilita compreender o modo que constitui o processo de saúde-doença, assim como aparece como indicativo de métodos inovadores, especialmente quando voltados para as formas de enfrentamento no cenário escolar à luz da percepção expressa pelos jovens. 
A este respeito, cabe citar McCowan (2015) quando destaca o império do discurso capitalista na educação quando coloca que "o Banco Mundial, que não aborda a educação como um direito fundamental, mas apoia a expansão dos sistemas escolares”. Essa abordagem cria um campo latente para descontinuidades encontradas nas escolas, uma vez que visa o acesso a instituição em detrimento das situações de permanência nas escolas, não contemplando o que se entende por meio puros de promoção da não-violência, ou melhor, da promoção de direitos, mas por uma ordenação comercial que desvirtua e alimenta o temor. Igualmente, aponta a necessidade de voltar o ensino e a educação às orientações da Declaração Universal dos Direitos Humanos (BRASIL, 1988), que determina que todo ser humano tem direito a instrução, especialmente frente ao que diz o artigo 26, parágrafo 2.

A instrução será orientada no sentido do pleno desenvolvimento da personalidade humana e do fortalecimento do respeito pelos direitos humanos e pelas liberdades fundamentais. A instrução promoverá a compreensão, a tolerância e a amizade entre todas as nações e grupos raciais ou religiosos, e coadjuvar as atividades das Nações Unidas em prol da manutenção da paz (BRASIL, 1988, p. 37).

Logo, para preservação da finalidade básica os ambientes de aprendizagem precisam entender as interseccionalidades desse meio como capazes de potencializar as prerrogativas humanísticas. As situações de criminalização da sexualidade, por exemplo, especialmente das identidades LGBTs são operadas por lógicas de controle social que violentam as subjetividades. Nesse sentido, Foucault (2009) sustenta a importância das investigações dos discursos presentes na educação, sendo esta a possibilidade de contribuição social deste estudo com vistas para o cuidado requerido a juventude.

A comunicação aqui proposta, entre os processos psíquicos e as questões sociológicas, é que através da investigação das percepções dos alunos, que envolvem também a nas narrativas dos escolares sobre violência, nos defrontamos com nossa história ou nosso passado, aceitando pensar de outra forma o agora que não é tão evidente sobre a violência. Portanto, pensar nos sintomas que manifestam a violência escolar, amplia o olhar não apenas para a manifestação presente, mas também para o conjunto de relações que promovem o aparecimento histórico de um objeto em discurso. 


\section{METODOLOGIA}

Com enfoque na interpretação e no contexto do objeto pesquisado, este estudo se apresenta com abordagem qualitativa, que está aliado à natureza da pesquisa aplicada, uma vez que busca produzir um aportes para teórico para a mediação no processo de investigação sobre a percepção de jovens matriculados no ensino médio. A pesquisa ainda traz Weber (2008) como seu método interpretativo para buscar, portanto, explicitar como a produção do saber científico, é condicionada a partir do contexto histórico do pesquisador vindo a influenciar a escolha do objeto e até o método de pesquisa, pois, o pesquisador deve ter a consciência das afetividades e motivações enxergadas na pesquisa.

\section{OBJETIVOS}

Quanto aos objetivos é uma pesquisa descritiva, explicativa, quando pretende identificar e explicar as concepções que circundam a percepção desse público. Para tanto realizou-se o levantamento bibliográfico dos documentos eletrônicos disponíveis, com o objetivo de conhecer as investigações sobre a percepção de violência entre alunos do ensino médio, no contexto escolar.

A dinâmica desta fase consistiu na pesquisa de artigos publicados em periódicos científicos na base eletrônica de dados LILACS (Literatura Latino-Americana em Ciências da Saúde). A Base LILACS foi escolhida pelo acesso gratuito e por ser um indexador que consta na lista Qualis (CAPES). A busca aconteceu no domínio do Portal Regional da Biblioteca Virtual em Saúde (BVS Brasil) sob a consulta dos títulos em "violência na escola" e "violência escolar". Posteriormente foram lidos todos os resumos com objetivo de selecionar aqueles que se referiam diretamente ao tema da concepção de violência feita por escolares matriculados no ensino médio. Os artigos foram organizados de modo que viabilizasse a identificação do título, autores, ano de publicação e conformidade com o objeto da pesquisa.

Após o levantamento a amostragem coletada percorreu roteiro contíguo de revisão integrativa em busca de compreender e identificar as lacunas que emergem com o fenômeno estudado (SOUZA, 2010). A pesquisa aconteceu no sentido de alcançar auxílio para a compreensão das principais formas de violência, dos significados de violência para os alunos, das narrativas sobre violência e por fim, para as formas de enfrentamento. Em seguida, após a leitura dos resumos, constatou-se que apenas 17 dos artigos auxiliam na identificação das principais formas de violência, 8 dos significados de violência para os 
alunos, 2 sobre as narrativas sobre violência, 7 para as formas de enfrentamento. os referenciais teóricos com vistas para a apresentação da síntese dos conhecimentos.

Verificou-se, após a leitura completa dos artigos, que dos 15, somente 11, abordavam relações agressivas entre alunos, 3 relatavam relações agressivas entre educadores e alunos e 1 artigo indicava interações agressivas entre os educadores. Dos onze artigos que abordavam as relações agressivas entre alunos, apenas cinco entraram nos critérios inclusão. Os artigos considerados para análise neste estudo estão relacionados no Quadro 1.

\section{RESULTADOS E DISCUSSÃO}

A pesquisa na base de dados sinalizou que 74 artigos responderam ao padrão utilizado na busca, nos quais, com 25 artigos analisados, 61 permanecem selecionados frente aos aspectos que contribuem na construção do referencial de cada objetivo específico, ficando assim disponibilizados:

\section{a) Principais formas de violência de enfrentamento:}

1.Autopercepção negativa de saúde associada à violência escolar em adolescentes / Negative self-perceived health associated with school violence in adolescentes;

2.Violência simbólica en la educación física escolar: un análisis crítico de las experiencias negativas del futuro profesorado de educación primaria / Violência simbólica na educação física escolar: uma análise crítica das experiências negativas do futuro docente de educação primária / Symbolic violence in school physical education: a critical analysis of the negative experiences of future teachers in primary education;

3.Tendências de situações de violência vivenciadas por adolescentes brasileiros: Pesquisa Nacional de Saúde do Escolar 2009, 2012 e 2015 / Trends in violent situations experienced by Brazilian adolescents: National Adolescent Student Health Survey 2009, 2012, and 2015;

4.Variables psicológicas comunes en la violencia escolar entre iguales y la 
violencia filio-parental: un estudio cualitativo / Psychological variables common in school violence between peers and filial-parental violence: a qualitative study / Variáveis psicológicas comuns na violência escolar entre iguais e a violência filio-parental: um estudo qualitativo;

5. La violencia escolar en perspectiva histórica. Buenos aires, 1969-2010* / A historical perspective on school violence. Buenos Aires, 1969-2010 / A violência escolar em perspectiva histórica. Buenos Aires, 1969-2010;

6. Necesidades educativas del estudiantado y personal docente respecto delfenómeno de la violencia escolar / Educational needs of students and teachers about the phenomenon of school violence / Necessidades educativas dos estudantes e pessoal docente em relação ao fenômeno da violência escolar;

7. Discutindo a indisciplina, a violência e o bullying na instituição escolar / Discussing theindiscipline, violence and bullyingin school / Discutiendolaindisciplina, violencia y bullying en la escuela;

8. Violencia escolar y consumo de alcohol en adolescentes en etapa de secundaria. Monterrey, México / Scholar violence and alcohol consumption in junior high school stage adolescents. Monterrey, Mexico;

9. Violencia escolar en adolescentes: un análisis en función de la actividad física y lugar de residencia habitual / School violence in adolescents: A analysis based on physical activity and place of residence;

10. Compreensão da violência escolar para os atores sociais de uma instituição de ensino / The understanding of school violence by the social actors of an educational institution;

11. Violencia escolar en adolescentes de una Escuela Secundaria Básica en el Campo, 2014-2015 / School violence in teenagers Schedule of educational involvement at high school in the campsite, 2014-2015;

12. Características da violência escolar no Brasil: revisão sistemática de estudos quantitativos / Characteristics of school violence in Brazil: a systematic review of quantitative studies;

13. Violência e bullying: manifestações e consequências nas aulas de Educação Física escolar / Violence and bullying: expressions and consequences of 
Physical Education classes / Violencia y bullying: manifestaciones y consecuencias em las clases de Educación ;

14. Um estudo sobre jovens e violência no espaço escolar / Un estudio sobre juventud y violencia en la escuela / A study on youth and violence at school;

15. Violência escolar: uma percepção da causa na visão do profissional não docente / La violencia escolar: una percepción de la causa desde el punto de vista del profesional no docente / School violence: an awareness of the cause in view of the nonteaching professional;

16. Intimidações na adolescência: expressões da violência entre pares na cultura escolar / Intimidation in adolescence: expressions of peer violence in school culture;

17. Estatus sociométrico y violencia escolar en adolescentes: implicaciones de la autoestima, la familia y la escuela / Sociometric status and school violence on adolescents: implications of self-esteem, family and school;

18. A violência familiar como fator de risco para o bullying escolar: contexto e possibilidades de intervenção / Family violence as a risk factor for school bullying: context and possibilities for intervention / La violencia familiar como factor de riesgo para el bullying escolar: contexto y posibilidades de intervención;

19. Vivências no espaço escolar de adolescentes vítimas de violência doméstica em acolhimento institucional / School experiences for institutionalized adolescents victims of domestic violence / Vivencias en el espacio escolar de adolescentes víctimas de violencia doméstica en acogida institucional;

20. Vivência de violência entre escolares brasileiros: resultados da Pesquisa Nacional de Saúde do Escolar (PeNSE) / Violence exposures by school children in Brazil: results from the National Adolescent School-based Health Survey (PeNSE);

21. A violência escolar no contexto de privação de liberdade / School violence in the context of deprivation of freedom / La violencia escolar en el contexto de privación de libertad;

22. Função paterna e adolescência em suas relações com a violência escolar / Paternal function in adolescence and their relation to school violence;

23. Violencia escolar en adolescentes rechazados y aceptados: un análisis de 
sus relaciones con variables familiares y escolares / School - based violence on peer rejected and peer-accepted adolecents: an analysis of its relationships with family and school variable / Violência escolar em adolescentes rejeitados e aceitos: uma análise de suas relações com variáveis e escolares;

24. Factores de riesgo de violencia escolar (bullying) severa en colegios privados de tres zonas de la sierra del Perú / Severe bullying risk factors in three Peruvian highland private schools;

25. Lesões no complexo maxilofacial em vítimas de violência no ambiente escolar / Maxillo facial injuries in victims of violence at school environment;

26. Agresión y violencia en la escuela como factor de riesgo del aprendizaje escolar / Aggression and violence in school as a risk factor of school education;

27. Estudio cualitativo de los determinantes de la violencia escolar en Chile / Qualitative study of school violence determinants in Chile;

28. Avaliação do conceito de violência no ambiente escolar: visão do professor / Evaluation of the violence concept in the school environment: the teacher's view;

29. O internato escolar como instituição total: violência e subjetividade / Boarding school as a total institution: violence and subjectivity;

\section{b) Significados que os alunos atribuem para a violência na escola:}

1.Tendências de situações de violência vivenciadas por adolescentes brasileiros: Pesquisa Nacional de Saúde do Escolar 2009, 2012 e 2015 / Trends in violent situations experienced by Brazilian adolescents: National Adolescent Student Health Survey 2009, 2012, and 2015;

2.Violência escolar: percepções de alunos e professores de uma escola pública / School violence: perceptions of students and teachers of a public school / Violencia escolar: percepciones de alumnos y profesores de una escuela pública;

3.Resilience processes within the school context of adolescents with sexual violence history / Processos de resiliência no contexto escolar de adolescentes com histórico de violência sexual; 
4. Violência no contexto escolar: significados para professores do ensino público;

/ Violencia en el contexto escolar: significados para profesores de la enseñanza pública / Violence and the school context: meanings for public education teachers;

5. Percepções de Adolescentes Escolares sobre as Relações entre Violência Doméstica e Bullying / Perception of School Adolescents about the Relationships between Domestic Violence and Bullying / Percepciones del Adolescente Escolar sobre las Relaciones entre la Violencia Doméstica y el Acoso Escolar / Perceptions des Adolescents Scolarisés sur la Relation entre la Violence Familiale et L'intimidation;

6. Violência escolar: percepções de adolescentes / School violence: teen perceptions;

7. Representações sociais da violência escolar na expressão de jovens estudantes / Social representations of school violence according to the expressions of young students / Representaciones sociales de la violencia escolar en la expresión de jóvenes estudiantes;

8. Universo consensual de adolescentes acerca da violência escolar / Consensual universe of adolescents about school violence / Universo consensual de adolescentes acerca de la violencia escolar;

9. O entendimento da violência escolar na percepção de adolescentes / Understanding school violence from the adolescents point of view;

10. Concepciones y prácticas sobre la violencia en el ámbito escolar / Concepts and practises of violence in school settings;

11. Validade e consistência interma do questionário de investigação de prevalência de violência escolar: versão estudantes / Validity and internal consistency of the school violence prevalence investigation questionnaire: student version;

12. Avaliação do conceito de violência no ambiente escolar: visão do professor / Evaluation of the violence concept in the school environment: the teacher's view;

13. Violência: paradoxos, perplexidades e reflexos no cotidiano escolar / Violence: paradoxes, perplexities, and reflexes on daily school routines; 
c) Análise das narrativas dos alunos sobre o motivo da violência escolar:

14. La radio escolar como herramienta de prevención de la violencia en la escuela;

15. Intimidações na adolescência: expressões da violência entre pares na cultura escolar / Intimidation in adolescence: expressions of peer violence in school culture;

16. Representações sociais da violência escolar na expressão de jovens estudantes / Social representations of school violence according to the expressions of young students / Representaciones sociales de la violencia escolar en la expresión de jóvenes estudiantes;

17. Universo consensual de adolescentes acerca da violência escolar / Consensual universe of adolescents about school violence / Universo consensual de adolescentes acerca de la violencia escolar;

18. Crianças em risco psicossocial associado à violência doméstica: o desempenho escolar e o autoconceito como condições de proteção / Children in psychosocial risk associated with domestic violence: school achievement and selfconcept as protection conditions.;

b) Identificar as formas de enfrentamentos propostas pelos alunos frente a violência na escola:

1. Institutional links to cope with school violence: an exploratory study / Vínculos institucionales para el afrontamiento de la violencia escolar: un estudio exploratorio / Vínculosinstitucionais para o enfrentamento da violência escolar: um estudo exploratório;

2. Discutindo a indisciplina, a violência e o bullying na instituição escolar / Discussing the indiscipline, violence and bullying in school / Discutiendo la indisciplina, violencia y bullying en la escuela;

3. Evaluation of a Brazilian School Violence Prevention Program (Violência Nota Zero) / Evaluación de un programa brasileño de prevención de la violencia escolar (Violência Nota Zero) / Avaliação dum programa brasileiro de prevenção de violência escolar (Violência Nota Zero);

4. Adolescência, violência e objetos culturais: uma intervenção entre o educativo 
e o terapêutico no espaço escolar / Adolescence, violence and cultural objects: an intervention between the educational and therapeutic at the school space / Adolescencia, violencia y objetos culturales: uma intervención entre el educativo y el terapéutico en la escuela

5. Enfrentamento da violência no ambiente escolar na perspectiva dos diferentes atores / Coping with violence in the school enviroment from the perspectives of different palyers / Enfrientamiento de la violencia em el ambiente escolar bajo la perspectiva de los diferentes actores;

6. Intervenção educativa sobre violência com adolescentes: possibilidade para a enfermagem no contexto escolar / Intervención educativa sobre la violencia con adolescentes: posibilidad para la enfermería en el contexto escolar / Educational intervention using the life activity of breathing with adolescentes;

7. Violência escolar na perspectiva de adolescentes: potencialidades para o enfrentamento / Violencia escolar en la perspectiva de adolescentes: potencialidades para el afrontamiento / School violence in the view of adolescents: possibilities for its confrontation;

8. La radio escolar como herramienta de prevención de la violencia en la escuela;

9. Violência escolar: uma percepção da causa na visão do profissional não docente / La violencia escolar: una percepción de la causa desde el punto de vista del profesional no docente / School violence: an awareness of the cause in view of the non-teaching profesional;

10. Identificação e caracterização da violência escolar: subsídios para ações de enfrentamento/ Identification and characterization of violence in school: subsidies for prevention and confrontation actions;

11. Prevenção da violência escolar: avaliação de um programa de intervenção / Preventing school violence: an evaluation of an intervention program / Prevención de la violencia escolar: evaluación de un programa de intervención;

12 Projeto "Abrace Seu Bairro": prevenção da violência no meio escolar e melhoria da qualidade de vida / Program Embrace Your Neighborhood: violence prevention at the school and quality of life / Proyecto "Abrace Su Barrio": prevención de la violencia en la escuela y calidad de vida;

13. Validade e consistência interma do questionário de investigação de prevalência 
de violência escolar: versão estudantes / Validity and internal consistency of the school violence prevalence investigation questionnaire: student version;

14. Prevención de la violencia y el fracaso escolar / Prevention of violence and school failure;

Osresultadosdaspesquisasanalisadasmostramqueasvariáveisfamiliaresserelacionam de modo diferente com a violência escolar em adolescentes rejeitados e aceitos: a autoestima familiar exerce um efeito direto na violência escolarno grupo de rejeitados e um efeito indireto em adolescentes aceitos, entretanto, o apoio dos pais se relaciona com a autoestima escolar no grupo de aceitos, porém, não no grupo de rejeitados. (MARTINEZ FERRER, 2010).

O estudo da Faculdade de Medicina da Universidade nacional de San Marco, Lima no Peru. mostrou a situação de violência escolar severa relacionada coloca como ponto importante paraidentificar as principais formas de violência a reação a reação dos pais aoevento, a exposição a ameaças, a presença de gangues e de amigos com alguma deficiência física (AMEMIYA, OLIVEROS, BARRENTOS, 2009). Em outra produção latino-americana a abordagem qualitativa apresentou a violência escolar com base na percepção dos estudantes de ensino médio no qual surgiram variáveis associadas à situação de violência como a trajetória fora do ambiente escolar, fatores de risco e fatores de influência positiva.

Partindo da teoria das representações sociais de Moscovici esta pesquisa modelou os antecedentes, mediadores e gatilhos como representações subjetivas e intersubjetivas que os jovens constroem na convivência escolar e concluiu que tais fatores partem, principalmente, do manejo disciplinar com a necessidade de reconhecimento dos pares, no qual destaca que, o disciplinamento escolar, dobra vontades mas não forma sujeito e, ainda, que aqueles que exibem comportamentos agressivos são os mesmo que se apresentam mais ressentimentos dentro da amostra, evidenciando assim o caráter simbólico da necessidade de reconhecimento apontada como fator preponderante para a violência escolar. Nesse sentido, Benelli (2002) complementa com seu estudo quando discute, a partir de hipóteses psicanalíticas, alguns aspectos da violência e subjetividade na instituição total e equipara os fins educativos do internato escolar são correspondentes aos objetivos terapêutico-correcionais do hospital psiquiátrico e da prisão.

Na porção quantitativa analisada sobre lesões físicas nas regiões da cabeça e face, observou-se que 61,9\% das vítimas eram do gênero masculino, sendo a faixa etária de 13 a 17 anos a mais atingida, no qual a face típica dos perpetradores são os colegas (92,9\%), enquanto os professores foram os agressores em 7,1\% dos casos (CAVALCANTI, 2009). 
Para Cid H. et. al.(2008) esse fenômeno está associado a vários fatores, tanto da criança como de sua família, de sua escola e ambiente social e que a medida diminuir este problema está na participação da comunidade escolar no estabelecimento de normas de respeito nos estabelecimentos escolares que incluam as relações entre alunos, professores, advogados, gestores, pessoal administrativo e pessoal de saúde.

Autores como Gilbert Durand, Edgar Morin e Paula Carvalho foram identificados em diálogocom a teoria do imaginário, da complexidade e da culturanálise de grupo por LOUREIRO,(1999) para a discussão da violência como fenômeno em atenção para a dimensão simbólica na construção de significados sobre o tema.

No âmbito das formas de enfrentamento foi analisado um projeto que fez uso da teoria psicanalíticapara interpretarconteúdosinconscientes, devivênciasprimitivas evínculos atuaisna vivência de grupos visando demonstrar as motivações que exibem aspectos defensivos e projetivos que influenciam na convivência entre pares. A intervenção ocorreu com equipe multidisciplinar que oferece modelos para os jovens se identificarem, ao mesmo tempo possibilitou a reflexão e fortalecimento dos vínculos. A escuta analítica foi usada no sentido de observar os possíveis focos de violência, os alunos da escola pública se mostraram mais participativos em relação com o público da rede privada, este último perfil foi descrito como apático entendido como um reflexo da escola privada que normalmente toma iniciativas pelos alunos ao invés de cultivar a autonomia.(LEVISKY, 2009).

\section{CONSIDERAÇÕES FINAIS}

As principais incursões extraídas durante o processo desta pesquisa estão, a priori, relacionadas ao funcionamento interpessoal dos educandos dentro da instituição escolar apresentando, portanto, novas formas de reproduzir violência (WEBER, 1982) para neutralizar e organizar aquele espaço. Dentro disso, notamos que as instâncias que configuram hoje uma forma permanente e dinâmica de relação (ELIAS, 1970; SETTON, 2002) são um conceito contemporâneo de sociabilidade.

Para tanto, indivíduos passam a ser mediados e reconfigurados por sua coexistência em distintas instâncias produtoras de valores culturais e referências identitárias. Enxerga-se na violência simbólica uma reclassificação de como é interpretado o babitus (BOURDIEU, 1989) no ambiente escolar. As relações de interdependência estabelecem entre rupturas e continuidades (SETTON, 2002), tomando para a conclusão da discussão nesta pesquisa, a escola serve como fator decisivo para que o aparelho da violência simbólico se mantenha em constante funcionamento.

Diante disso, é considerado pertinente reforçar a violência como parte engendrada do meio escolar, como estruturada e estruturante (WEBER, 1982), formando um sistema típico de reforço para legitimar a dominação 
atribuindo força às relações de força maior, buscando fundamentá-las e contribuindo, portanto, para a dominação de indivíduos já adequados e dominados dentro de um sistema.

\section{REFERÊNCIAS}

ALVES-MAZZOTTI, Alda Judith. Relevância e aplicabilidade da pesquisa em educação. Cadernos de pesquisa, v. 113, p. 39-50, 2001.

Representações sociais: aspectos teóricos e aplicações à educação.Em aberto, v. 14, n. 61, 2008.

ALVES-MAZZOTTI, Alda Judith et al. Os sentidos do ser professor. Revista Educação e Cultura Contemporânea, v. 1, n. 1, p. 61-73, 2016.

AMEMIYA, I.; OLIVEROS, M.; BARRIENTOS, A. Factores de riesgo de violencia escolar (bullying) severa en colegios privados de tres zonas de la sierra del Perú. In: Anales de la Facultad de Medicina. UNMSM. Facultad de Medicina, 2009. p. 255-258.

BENELLI, Sílvio José. $\mathbf{O}$ internato escolar como instituição total: violência e subjetividade.

Internet (documentos eletrônicos): Psicol. estud., Maringá , v. 7, n. 2, p. 19-29, Dec. 2002 . Available from $\leq \mathrm{http}: / /$ www.scielo.br/scielo.php?script $=$ sci arttext\&pid=S1413-73722002000200004\&lng $=\mathrm{e}$ n\&nrm=iso $>$. access on 07 Mar. 2019. http://dx.doi.org/10.1590/S1413- 73722002000200004.

BRASIL. Representação da UNESCO. Declaração universal dos direitos humanos. 1988.

BOURDIEU, P. O poder simbólico. Rio de Janeiro: Bertrand Brasil S. A., 1989. BRASIL, Katia Cristina Tarouquella Rodrigues et al. Adolescência, violência e objetos culturais: uma intervenção entre o educativo e o terapêutico no espaço escolar. Estilos da Clinica, v. 20, n. 2, p. 205-225, 2015.

BRINGIOTTTI, María Inés; KRYNVENIUK, Marta; LASSO, Silvia. Las multiples violéncias de la violencia. Paidéia, v. 14, n. 29, 2004.

CARVALHO, Rachel de. Revisão integrativa: o que é e como fazer. Einstein, v. 8, n. 1 Pt 1, p. 102-6, 2010. UNI. Relatório Anual UNI 2017. Unicef. Brasília, DF. Ano $14 \cdot n^{\circ}$ 39. Março de 2018. 20. Disponível em: <https://www.unicef.org/brazil/pt/UNI_39.pdf>

CAVALCANTI, A. L. Lesões no complexo maxilofacial em vítimas de violência no ambiente escolar. Ciência \& Saúde Coletiva, v. 14, p. 1835- 1842, 2009.

CID H, PATRICIA et al . AGRESIÓN Y VIOLENCIA EN LA ESCUELA COMO FACTOR DE RIESGO DEL APRENDIZAJE ESCOLAR. Cienc. enferm., Concepción , v. 14, n. 2, p. 21-30, dic. 2008 . Disponible en $<$ https://scielo.conicyt.cl/scielo.php?script=sci_arttext\&pid=S071795532008000200004\&lng=es\&nrm=iso $>$. accedido em 15 enero 2019. http://dx.doi.org/10.4067/S0717- 95532008000200004

CHARLOT, Bernard. A violência na escola: como os sociólogos franceses abordam essa questão. Sociologias, v. 4, n. 8, 2002.

CRUZ, M.G.A.; FERRAZZA, D.A.; JUNIOR, H.R.C. Projeto de Lei sobre a Medicalização da Educação: Biopolítica, Controle e Resistência na Contemporaneidade. Nuances: estudos sobre Educação, Presidente Prudente-SP, v. 25, n. 2, p. 210-233, maio/ago. 2014. 
ELIAS, Norbert. Introdução à Sociologia. Tradução Maria Luísa Ribeiro Ferreira. Braga, Portugal: Editora Pax Limitada, 1980.

FOUCAULT, M. Vigiar e Punir. Petrópolis: Vozes, 2009.

FREUD, Sigmund. O inconsciente (1915). Obras completas, v. 14, 1996.

Instituto Brasileiro de Geografia e Estatística. Pesquisa Nacional de Saúde do Escolar (PeNSE) 2015. Rio de Janeiro: IBGE; 2016. 126 p.

LACAN, J. Função e campo da fala e da linguagem em psicanálise. Em Escritos (pp. 238-324). Rio de Janeiro: Jorge Zahar, 1998. Disponível em $<\underline{\text { https: / / pt.scribd.com/document/339009688/1953-Funcao-e-Campo-Da-Fala-e-Da- Linguage }}$ m-Em-Psicanalise-in-Escritos-Jacques-Lacan-OCR > Acesso em 2 de novembro de 2018.

LEVISKY, Ruth Blay. Projeto "Abrace Seu Bairro": prevenção da violência no meio escolar e melhoria da qualidade de vida. Rev. SPAGESP, Ribeirão Preto , v. 10, n. 2, p. 33-38, dez. 2009 . Disponível em $\quad \leq$ http://pepsic.bvsalud.org/scielo.php?script=sci arttext\&pid=S167729702009000200006\&ln $\mathrm{g}=$ pt\&nrm=iso >. acessos em 17 fev. 2019.

MARTINEZ FERRER, Belén et al . Violencia escolar en adolescentes rechazados y aceptados: un análisis de sus relaciones con variables familiares y escolares. Psicol. teor. Prat., São Paulo, v. 12, n. 2, p. 03-16, fev. $2010 \quad$ D $\quad$ Disponível em $\leq$ http://pepsic.bvsalud.org/scielo.php?script=sci arttext\&pid=S1516- $\quad \underline{36872010000200002 \& l n}$ $\mathrm{g}=\mathrm{pt} \& \mathrm{nrm}=$ iso $>$. acessos em 14 fev. 2019.)

MCCOWAN, Tristan. O direito humano à aprendizagem e a aprendizagem dos direitos humanos.

Educar em Revista, v. 31, n. 55, p. 25-46, 2015.

NOGUEIRA, Analuiza Mendes Pinto. Angústia e violência: sua incidência na subjetividade. Rev.

Latinoam. Psicopatol. Fundam. São

Paulo, v. 4,n.1,p. 76-85, mar. 2001.Disponívelem

$<$ http://www.scielo.br/scielo.php?script $=$ sci arttext\&pid=S1415- 47142001000100076\&lng $=\mathrm{e}$

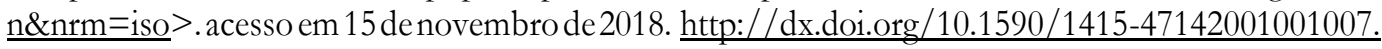

SETTON, M. G. J. A teoria do habitus em Pierre Bourdieu: uma leitura contemporânea. São Paulo: Revista Brasileira de Educação, 2002.

Internet (documentos eletrônicos): SOUZA, Marcela Tavares de; SILVA, Michelly Dias da;

WEBER, M. Ensaios de sociologia. Organização: GERTH, H. H. WRIGHT MILLS, C. Rio de Janeiro: Ed. LTC. 1982. 